\title{
Museo Reiss-Engelhorn contra Wikimedia: La protección de reproducciones fotográficas
}

\author{
Reiss-Engelhorn Museum versus Wikimedia: \\ The Protection of Photographic Reproductions
}

NICOLÁS BELLO LAGOS

Abogado independiente, Chile

RESUMEN El artículo examina la sentencia dictada el año 2016 en Alemania en una causa entre la fundación Wikimedia y el Museo ReissEngelhorn. El fallo reconoce los derechos que el museo tiene sobre las reproducciones de las obras de arte que alberga, incluidas aquellas que se encuentran basadas en obras pertenecientes al dominio público. Además de los fundamentos ocupados por el tribunal, se plantean también algunas interrogantes en torno a los efectos de una decisión como la adoptada por la sentencia, relacionadas con el acceso a la cultura.

PALABRAS CLAVe Derecho de autor, dominio público, acceso a la cultura, digitalización, reproducciones, fotografía.

ABSTRACT This article examines the 2016 German ruling of a trial between the Wikimedia Foundation and the Reiss-Engelhorn Museum. The ruling recognizes the right that the museum has over the reproductions of the works of art it owns, including those that are based on public domain works. In addition to the grounds occupied by the court, the article also raises some questions about the effects of a decision such as the one adopted by the ruling, relating to access to culture. 
KEYWORDS Copyright, public domain, access to culture, digitization, reproductions, photography.

\section{INTRODUCCIÓN}

Por más de una década, la fundación sin fines de lucro Wikimedia se ha dedicado a promover la cultura libre a través de sus numerosos proyectos. Su iniciativa más exitosa es Wikipedia, una enciclopedia en línea que es editada de manera colaborativa por miles de usuarios, y que es actualmente uno de los sitios web más visitados del planeta. Debido a que su contenido es publicado a través de la Licencia Creative Commons Atribución Compartir Igual 3.0, los artículos de esta enciclopedia pueden ser reutilizados por cualquier persona sin grandes restricciones, incluso con fines comerciales. ${ }^{\text {I }} \mathrm{Su}$ deseo por fomentar una mayor flexibilización respecto de los derechos de autor también se puede ver en Wikimedia Commons, un repositorio que almacena archivos multimedia que poseen alguna licencia libre o se encuentran en el dominio público, lo que les permite ser utilizados por otras personas sin mayores limitaciones.

Sin embargo, su misión no ha estado exenta de dificultades. Al promover un uso de las obras y de los derechos patrimoniales sobre éstas más flexible que el habitual, Wikimedia ha tenido algunos desacuerdos con personas o instituciones que pretenden ejercer un mayor control sobre esta área del derecho. Así ha ocurrido con un tema como el de la reproducción de obras que se encuentran en el dominio público, que ha generado un debate en torno a la posibilidad de proteger aquellas copias que se hacen sobre obras que no están sujetas a las restricciones del derecho de autor. Wikimedia ha sostenido que las reproducciones digitales que suben a sus servidores no se encuentran sujetas a derecho de autor ya que las obras que sirvieron como base tampoco lo están, mientras que

\footnotetext{
I. En base a esta licencia, cualquier persona puede copiar y redistribuir el material en cualquier medio o formato, así como remezclar, transformar y crear nuevas obras a partir de dicho material, para cualquier finalidad, incluso comercial. Las condiciones que se deben cumplir es reconocer adecuadamente la autoría del material y, en caso de remezclar, transformar o crear una nueva obra utilizando aquel material como base, difundir ese resultado bajo la misma licencia que el original. Véase https://creativecommons.org/ licenses/by-sa/3.o/legalcode.
} 
las instituciones que se dedican a hacer dichas reproducciones en alta resolución y a comercializarlas argumentan que al cambiar el medio en el que se encontraba la obra han creado un nuevo trabajo, el que es capaz de ser protegido bajo los principios del derecho de autor.

En 2009, la National Portrait Gallery de Londres se contactó con Wikimedia alegando la infracción de los derechos de autor que la galería británica tenía supuestamente sobre las reproducciones fotográficas de las pinturas de su colección. ${ }^{2}$ El caso no llegó a un desenlace definitivo, dado que la galería de arte no acudió a la vía judicial. La institución decidió permitir el uso gratuito de algunas de sus reproducciones, las que son de menor resolución que aquellas que facilita a cambio del pago de una licencia; ${ }^{3}$ Wikimedia, por su parte, todavía alberga en sus servidores las imágenes que dieron origen a la controversia.

El resultado fue distinto en el caso que se estudiará en el presente artículo, que comenzó el año 20 I 5 a través de una demanda que el museo alemán Reiss-Engelhorn interpuso en contra de Wikimedia. ${ }^{4}$ El desacuerdo es similar al que existió con la National Portrait Gallery, girando en torno a la posible protección que puede recaer sobre reproducciones de obras que se encuentran en el dominio público. La diferencia es que en esta ocasión fue un tribunal el que dirimió el asunto, acogiendo la pretensión del museo y estableciendo que Wikimedia infringió los derechos que dicha institución tenía sobre esas reproducciones fotográficas.

Si bien Wikimedia señaló que apelaría el fallo, de todas maneras resulta relevante analizar las implicancias de la decisión y los argumentos que llevaron al tribunal a acoger la demanda. En el presente artículo se examina el razonamiento ocupado por el Tribunal de Distrito de Berlín para aceptar la postura del museo, en base a los criterios de protección generalmente ocupados dentro del derecho de autor, el tipo de obra al que pueden ser asimiladas las fotografías, y esbozando algunas conse-

2. "Gallery in Wikipedia legal threat", BBC News, I 5 de julio de 2009 , disponible en http://news.bbc.co.uk/2/hi/entertainment/arts_and_culture/8 I 5 I989.stm.

3. National Portrait Gallery, «Use this image», disponible en http://www.npg.org.uk/ collections/search/use-this-image.php?mkey=mwo22 38 .

4. International Communia Association, «Why is a museum suing Wikipedia for sharing?», 24 de noviembre de 2015 , disponible en http://www.communia-association. org/20 5/I I/24/why-is-a-museum-suing-wikipedia-for-sharing/. 
cuencias que este tipo de decisión puede tener sobre principios como el acceso a la cultura.

\section{LA SENTENCIA}

La causa involucró una serie de reproducciones fotográficas que el museo le había encargado hacer a un fotógrafo profesional. Estas imágenes en alta resolución fueron incorporadas en un catálogo de exhibición del museo, publicado en I992, siendo posteriormente escaneadas y subidas por un usuario a Wikimedia Commons bajo el fundamento de que estaban en el dominio público, dado que la fecha de fallecimiento de los autores de las obras no les permitía estar protegidas por el derecho de autor. ${ }^{5}$ Una de las pinturas, por ejemplo, es un retrato del compositor alemán Richard Wagner realizado por Cäsar Willich, fallecido en I 886. $\mathrm{El}$ archivo tiene unas dimensiones de $22 \mathrm{I} 3 \times 2666$ píxeles y un peso de I, $85 \mathrm{MB}$, el que fue subido a Commons el $2 \mathrm{I}$ de octubre de $2006 .{ }^{6}$ Las I 7 fotografías en cuestión fueron subidas por el usuario entre los años 2006 y 2007.7

El juicio se llevó a cabo en contra de la Fundación Wikimedia, institución estadounidense a cargo de proyectos como Commons y Wikipedia, y también en contra de Wikimedia Alemania, capítulo local de la organización. La demanda sólo fue acogida respecto de la primera demandada, ya que el rol de Wikimedia Alemania en el caso en cuestión resultó imponderable, dado que no tenía injerencia alguna en las ediciones que los usuarios realizan en los diferentes proyectos ni podía modificarlas con posterioridad.

5. Actualmente, la regla general es que la protección conferida por el derecho de autor se extienda durante toda la vida del autor más los 70 años posteriores a su muerte. Si bien el Convenio de Berna establece un plazo de 50 años, varios países lo han aumentado a 70 en sus legislaciones. Es el caso de Chile, que lo establece así en el artículo ro de la Ley 17.336 de Propiedad Intelectual.

6. Wikimedia Commons, «File:Richard Wagner by Caesar Willich ca I862.jpg», disponible en https://commons.wikimedia.org/wiki/File:Richard_Wagner_by_Caesar_Willich_ca_i862.jpg.

7. Los archivos que fueron objeto de la demanda se encuentran disponibles en https:// commons.wikimedia.org/wiki/Category:Images_subject_to_Reiss_Engelhorn_Museum_ lawsuit. 
Según la demanda que interpuso el museo ante el Tribunal de Distrito de Berlín el 28 de octubre de 20 I 5 , la inversión de tiempo y esfuerzo, así como el empleo de la habilidad técnica utilizada por el fotógrafo para la creación de las reproducciones, son razones suficientes para proteger las fotografías de esas obras de arte. En base a este razonamiento, permitir que el trabajo realizado por el fotógrafo sea ocupado por terceros sin solicitar autorización ni entregar algún tipo de contraprestación resultaría contrario a derecho. Wikimedia, en tanto, hizo hincapié en el hecho de que las fotografías son reproducciones fieles de las obras originales, sin existir grandes variaciones entre ambas, lo que sumado al hecho de que las pinturas pertenecen al dominio público, no permitiría una protección para meras copias de dichas obras. ${ }^{8}$

En su sentencia de 3 I mayo de 20I6, el Tribunal de Berlín acogió la demanda del museo en contra de la Fundación Wikimedia, declarando que infringió los derechos que tenía sobre las reproducciones fotográficas de pinturas que formaban parte de su colección. El fallo tiene la particularidad de que está basado en una figura propia del derecho de autor alemán, que distingue dos categorías de fotografías capaces de ser protegidas. Por un lado se encuentran las obras fotográficas (Lichtbildwerke), que son aquellos trabajos que se enmarcan dentro de la definición de obra intelectual o artística, cumpliendo con los requisitos generales de protección, debiendo ser la expresión de una creación intelectual, reflejando la creatividad e impronta personal del autor. En la segunda categoría se encuentran las fotografías simples (Lichtbilder), que pese a no cumplir con este estándar artístico, son igualmente protegibles debido a la habilidad técnica que exige su creación, aunque en un menor grado. Mientras la protección de las obras fotográficas se extiende hasta los 70 años posteriores a la muerte del autor, las simples fotografías tienen un plazo de 50 años desde la fecha de su publicación o, en caso de no haber sido publicadas, desde que fueron tomadas.

La protección de las obras fotográficas se encuentra establecida en el artículo 2 de la Ley de Derecho de Autor de Alemania. Tras establecer

8. Tribunal de Distrito de Berlín, Reiss-Engelhorn Museum (REM) of the City of Mannheim v. Wikimedia Foundation Landgericht, I 5 O 428/I 5 (20I6). Disponible en https://wikimediafoundation.org/wiki/File:Reiss-Engelhorn_Museum_(REM)_of_the_ City_of_Mannheim_v._Wikimedia_Foundation_Landgericht.pdf. 
en el artículo I que la protección abarca a aquellos trabajos que hayan sido creados dentro del ámbito literario, científico o artístico, la norma enumera en el artículo siguiente los tipos de obras protegidas por el derecho de autor. Las obras fotográficas son incluidas en el quinto puesto. Mientras tanto, las fotografías simples se encuentran reguladas en el artículo 72 del mismo cuerpo legal, el que establece que este tipo de fotografías y otros trabajos creados a través de procedimientos similares, se encuentran protegidos a través de las normas aplicables a las obras fotográficas. ${ }^{9}$

El debate entre las partes se centró en ambas posturas, defendiendo el museo por una parte el trabajo que conllevó crear las reproducciones fotográficas, argumentando que en dicho caso se debe aplicar el artículo 72 de la Ley de Derecho de Autor alemana, mientras que la defensa de Wikimedia consistió en hacer hincapié en las similitudes entre las obras originales y las fotografías resultantes, así como en el ánimo del fotógrafo de crear reproducciones lo más fieles posible de las pinturas. Esta parte sostuvo que debido a la semejanza perseguida al momento de crear las fotografías, las reproducciones objeto del juicio no podían ni siquiera ser protegidas a través del artículo 72, como simples fotografías, ya que se trataba de una mera reproducción mecánica.

Debido a su carácter de reproducciones de obras preexistentes, el tribunal negó la protección de las imágenes del museo como obras fotográficas, ya que el objetivo del fotógrafo no consistió en alcanzar un resultado creativo, sino que en obtener un resultado lo más fiel posible al original. No tenía, por lo tanto, libertad artística, sino que una meta más bien técnica. La protección que le concede la sentencia se obtiene al aplicar esta figura perteneciente al derecho alemán, que recompensa el esfuerzo técnico invertido al momento de tomar una fotografía. Lograr una reproducción fiel de una pintura requiere un control preciso de factores como la iluminación, el contraste y la exposición, con tal de obtener un nivel alto de detalles y evitar distorsiones o reflejos indeseados. A juicio del tribunal, ese tipo de dedicación es suficiente para aceptar la protección que otorga la ley alemana.

De esta manera, el tribunal ordenó a Wikimedia dejar de poner a dis-

9. Una versión en inglés de la Ley de Derecho de Autor alemana está disponible en el siguiente enlace: https://www.gesetze-im-internet.de/englisch_urhg/englisch_urhg.html. 
posición del público dichas fotografías en Alemania, bajo la condición de pagar una multa de 250.000 euros en caso de contravenir la decisión. El resultado de este juicio aún no se encuentra firme, ya que Wikimedia anunció que apelará la sentencia.

\section{EL CRITERIO DE PROTECCIÓN}

Existen diversos criterios al momento de determinar qué obras merecen ser protegidas a través del derecho de autor. ${ }^{10}$ Las dos principales corrientes son la doctrina de la originalidad y el sweat of the brow. La primera de ellas puede ser definida de diferentes maneras, pero en todas esas concepciones el énfasis se encuentra en la forma de expresión de la obra, que debe reflejar la impronta personal del autor o tener características propias que la distingan de otra obra. En el caso del sweat of the brow (literalmente, «sudor de la frente»), lo que se protege es el trabajo que ha tomado crear la obra, es decir, el esfuerzo invertido en su realización. El foco, por lo tanto, radica en el proceso de creación mismo más que en el resultado (Newell, 20IO: I 5-I8).

Esta distinción resulta útil al momento de examinar la sentencia estudiada, ya que los dos tipos de fotografías reguladas por la ley alemana se enmarcan dentro de cada una de estas corrientes. Así, las obras fotográficas (Lichtbildwerke) deben cumplir el requisito general de la originalidad para poder ser protegidas, debiendo manifestar la expresión creativa de su autor, mientras que en las fotografías simples (Lichtbilder) se considera el trabajo que tomó crearlas para poder concederles protección legal. El mismo tribunal explica que las reproducciones fotográficas del museo no pueden ser protegidas como obras fotográficas ya que carecen de la originalidad necesaria, al ser copias serviles de las pinturas en las que están basadas. ${ }^{\text {II }}$

La figura de las fotografías simples puede ser equiparada con la protección sui generis que reciben las bases de datos bajo la normativa de la Unión Europea. La Directiva 96/9 CE le otorgó una protección jurídica a los creadores de bases de datos en aquellos casos que hayan incurrido

Io. Un examen más detallado de estos criterios y su aplicación a las reproducciones de obras en el dominio público se realizó en Bello Lagos (2014).

I I. Tribunal de Distrito de Berlín, Reiss-Engelhorn Museum (REM) of the City of Mannheim v. Wikimedia Foundation Landgericht, I 5 O 428/I 5 (2016). 
en una «inversión (financiera, en recursos humanos, esfuerzo y energía) efectuada en la obtención, la verificación o la presentación del contenido de una base de datos». Esta protección se diferencia de la que reciben las bases de datos por parte del derecho de autor, la que requiere de un criterio más estricto, al exigirse una creación intelectual en la selección o disposición de materias. ${ }^{\mathrm{I2}}$ Como ocurre con la distinción entre obras fotográficas o simples fotografías, la diferencia radica en que en un caso se requiere un cierto de grado de originalidad en el producto y en el otro basta con el esfuerzo utilizado.

Dado que la labor el fotógrafo consistió en imitar lo más fielmente posible la imagen que estaba capturando, la sentencia le niega protección en base al criterio de la originalidad, pero considera que el procedimiento involucrado es de tal complejidad que merece ser protegido a través de la segunda figura. Pero no cualquier tipo de esfuerzo puede ser premiado con este tipo de protección. El tribunal berlinés cita un fallo de 1989 emitido por el Tribunal Federal de Alemania, conocido como Bibelreproduktion, ${ }^{\mathrm{I} 3}$ para poder determinar la línea divisoria entre trabajos merecedores y no merecedores de protección. El caso giraba en torno a las reproducciones de unas biblias que contenían unos grabados del artista Matthäus Merian, grabados que se encontraban en el dominio público. La sentencia estableció que la reproducción realizada en aquella ocasión era simplemente mecánica, similar al de un proceso como la fotocopia, por lo que no era posible concederle la protección otorgada a las fotografías simples. ${ }^{\mathrm{I} 4}$

En base a este criterio, el tribunal berlinés concluyó que la fotografía de pinturas constituye un proceso más complejo, no meramente mecánico, que requiere el ajuste de diversas variables para obtener un producto satisfactorio, por lo que merecería la protección establecida en la ley de derecho de autor alemana.

I 2. Directiva 96/9 CE, disponible en http://eur-lex.europa.eu/LexUriServ/LexUriServ. do?uri=CELEX:3 1996Looo9:ES:HTML.

I3. Tribunal Federal de Alemania, I ZR I4/88 (I989), disponible en https:// de.wikisource.org/wiki/Bundesgerichtshof_-_Bibelreproduktion.

I4. Este criterio fue también ocupado por el Tribunal Federal de Alemania en el fallo conocido como Telefonkarte, I ZR I46/98, del 7 de diciembre de 2000. 


\section{LA SENTENCIA A LA LUZ DE OTROS PRINCIPIOS DEL DERECHO DE AUTOR}

Mientras en el resto de los países se opta por uno u otro criterio de protección, la sentencia examinada demuestra que en Alemania se pueden ocupar los dos al momento de proteger las fotografías. Pese a ser una situación bastante particular, basada en disposiciones propias de aquel ordenamiento jurídico, la decisión adoptada por el tribunal de Berlín no carece de interés para el resto de los países, especialmente si consideramos las implicancias que una sentencia como ésta puede tener dentro del derecho de autor.

Aceptar la protección de reproducciones de obras que se encuentran en el dominio público levanta varias interrogantes, como cuál de los elementos presentes en esas obras nuevas están sujetos a esa protección. Considerando que estamos ante las llamadas obras derivadas, ya que se basan en una obra originaria o preexistente (las pinturas que sirven como base para las fotografías), ${ }^{\mathrm{I}}$ sólo los elementos adicionales serían capaces de ser protegidos por el derecho de autor, ya que la pintura original seguiría estando en el dominio público (Dobson, 2009: 326). ¿Cuál sería, entonces, ese elemento novedoso?

Como se trata de reproducciones que buscan ser lo más fieles a las pinturas en cuestión, el único cambio relevante sería el traspaso de un medio a otro. Es decir, desde el lienzo o muro en el que fue realizada la obra, a una superficie lisa como la fotografía análoga o un mapa de bits en el caso de que se trate de una fotografía digital. Este tipo de protección sería excesivamente amplio, ya que se estaría otorgando un monopolio sobre un medio en general, lo que convertiría a cualquier nuevo intento por fotografiar la misma pintura en una eventual infracción de los derechos de autor de quien realizó la primera reproducción. Además, es necesario considerar la distinción entre la obra en sí (la materialización de una idea) y su soporte material (el medio físico en el que se encuentra plasmada la obra), ya que lo que se está protegiendo a través del derecho de autor es el primer concepto.

Siendo las reproducciones de obras de arte —especialmente las re-

I 5. A modo de ejemplo, la Ley chilena de Propiedad Intelectual define a la obra derivada como "aquella que resulte de la adaptación, traducción u otra transformación de una obra originaria, siempre que constituya una creación autónoma» (artículo 5 letra i). 
producciones digitales - la principal forma que la mayoría de las personas tienen para poder conocer tales trabajos, las limitaciones que se establezcan sobre ellas pueden incidir directamente en dicho acceso. Si a esto se suma el hecho de que las galerías, archivos o museos donde se encuentran albergadas las obras deciden de manera discrecional quiénes pueden o no realizar reproducciones de aquellas obras, se crea un control efectivo sobre tales trabajos, aún en el caso de que los originales se encuentren en el dominio público. Uno de los aspectos que no recibe la suficiente atención al momento de hablar sobre los derechos de autor es la doble dimensión que alberga, entre lo público y lo privado, es decir, entre los autores y la sociedad (Ruiz Gallardo, 20I0: 5). Esto ya se encontraba reconocido en I948, en la Declaración Universal de Derechos Humanos, que en su artículo 27 establece:

I. Toda persona tiene derecho a tomar parte libremente en la vida cultural de la comunidad, a gozar de las artes y a participar en el progreso científico y en los beneficios que de él resulten.

2. Toda persona tiene derecho a la protección de los intereses morales y materiales que le correspondan por razón de las producciones científicas, literarias o artísticas de que sea autora.

Las restricciones al acceso de las obras materiales, así como la protección de las reproducciones que se hagan de ellas, pueden llegar a crear un verdadero derecho de autor a perpetuidad. La circunstancia de que la obra original entre al dominio público carecería de relevancia, ya que es a través de las reproducciones que se seguiría extendiendo el monopolio sobre su uso. La conducta que consiste en aseverar tener derechos de autor sobre obras que no lo tienen ha sido bautizada por Jason Mazzone como copyfraud, un acrónimo que combina las palabras copyright y fraud («fraude» o «estafa» en inglés) (Mazzone, 2006: I028). Se trata de un menoscabo a la figura del dominio público, el que cumple un importante rol dentro de la sociedad. Como ha señalado la Organización Mundial de la Propiedad Intelectual (OMPI), las obras en el dominio público «están al servicio de importantes objetivos sociales, como la educación, la investigación, la información, el entretenimiento, etcétera. Las obras más valiosas y más resistentes al paso del tiempo pueden llegar a ser patrimonio común de una nación o de toda la humanidad» (Ficsor, 2003: 48). 
Dentro del derecho estadounidense, un fallo importante sobre la protección de reproducciones fotográficas es el de Bridgeman Art Library v. Corel Corporation, emitido por el Tribunal del Distrito Sur de Nueva York en I999. La sentencia, que sigue el criterio de la originalidad como factor determinante al momento de proteger una obra a través del derecho de autor, sostuvo que el esfuerzo invertido y las habilidades necesarias para crear reproducciones fieles de obras preexistentes no son determinantes al momento de otorgarle protección a aquellos productos; lo importante radica en si el resultado introduce variaciones relevantes a la obra base, algo que no ocurre con las meras reproducciones (Matz, 2000). El negocio de la demandante consistía en vender licencias de uso sobre sus reproducciones de obras de arte. Si bien dichas obras estaban en el dominio público, los acuerdos de exclusividad que la empresa tenía con diferentes museos y galerías le permitía controlar el uso sobre dichas obras a través de sus reproducciones, utilizando el derecho de autor como una herramienta de control.

\section{CONCLUSIONES}

En 2009, en la causa Infopaq International A/S v. Danske Dagblades Forening, el Tribunal de Justicia de la Unión Europea sostuvo que las obras protegibles por el derecho de autor deben ser una expresión de la creación intelectual de su autor, lo que constituye un reconocimiento del requisito de la originalidad. ${ }^{16}$ En base a ese criterio resulta dudoso que las meras reproducciones de obras que se encuentran en el dominio público estén sujetas a la protección del derecho de autor. ${ }^{17}$

Sin embargo, hay que tener en cuenta que la decisión contenida en la sentencia comentada se basa en una disposición especial de la Ley de Derecho de Autor de Alemania, disposición que ha sido interpretada por el Tribunal Federal de aquel país como un reconocimiento del trabajo

I6. Tribunal de Justicia de la Unión Europea, Infopaq International A/S v. Danske Dagblades Forening, disponible en http://eur-lex.europa.eu/LexUriServ/LexUriServ.do? uri=CELEX:62008CJ0005:EN:HTML.

I7. Así, por ejemplo, lo ha entendido la Oficina de Propiedad Intelectual del Reino Unido. Véase «Copyright Notice: Digital images, photographs and the internet», p. 3, disponible en https://www.gov.uk/government/uploads/system/uploads/attachment_ data/file/48 I I 94/c-notice-20I40I.pdf. 
invertido al momento de crear una obra determinada, prescindiendo de la originalidad de su resultado. Reproducciones como la fotocopia o el escaneo de documentos pueden no ser lo suficientemente laboriosas para obtener una protección a través de esa particular institución del ordenamiento jurídico alemán, pero las dudas persisten en relación a las reproducciones fotográficas, que requieren de un proceso más complejo. Todo parece indicar que la decisión de este asunto dependerá del criterio que ocupen los tribunales superiores al momento de determinar si el esfuerzo ocupado por el fotógrafo es suficiente para concederle protección a sus reproducciones fotográficas o no. ${ }^{18}$

Cuestiones como ésta, que involucran ideas como el acceso a la cultura y el control de carácter monopólico sobre obras intelectuales, no sólo pueden ser analizadas desde una perspectiva jurídica, sino que requieren un examen más amplio. Que una de las partes involucradas sea un museo no es un aspecto menor, ya que es necesario considerar también la misión que ese tipo de instituciones deben cumplir en la sociedad y cómo su actuar puede afectar el vínculo que la población tiene con las obras que se encuentran bajo su protección. ${ }^{19}$ Resulta paradójico que en una época donde los avances tecnológicos permiten un acceso a la cultura que resultaba inimaginable décadas atrás, sobre todo gracias al desarrollo de internet, surjan nuevas y más férreas restricciones a dicho acceso.

\section{REFERENCIAS}

Bello Lagos, Nicolás (20I4). «La apropiación de obras en el dominio público a través de su digitalización». Revista Chilena de Derecho y Tecnología, 3 (2): I I-65. DOI: I0.5354/07I9-2584.20I4.3 I656.

Dobson, Kimberly N. (2009). «The originality of photographs for purposes of Copyright Law before and after Bridgeman Art Library, Ltd

I 8. Hay que considerar además algunas cuestiones jurídicas que escapan del marco de este artículo, como la legitimidad pasiva de la Fundación Wikimedia en casos como éste, al no tener un control sobre los contenidos subidos por sus usuarios, o incluso la competencia misma del tribunal, ya que los servidores de la fundación se encuentran en Estados Unidos, no en Alemania.

I9. Un análisis más completo de estos temas puede encontrarse en Petri (20I4). 
V. Corel Corp». Florida Coastal Law Review, Io: 319-347. Disponible en https://www.fcsl.edu/sites/fcsl.edu/files/dobson.pdf.

FICsOR, Mihaly (2003). Guía sobre los tratados de derecho de autor y derechos conexos administrados por la OMPI. Ginebra: Organización Mundial de la Propiedad Intelectual. Disponible en http://www. wipo.int/edocs/pubdocs/es/copyright/89I/wipo_pub_89I.pdf.

MAtz, Robert C. (2000). «Public domain works of art: Bridgeman Art Library, Ltd. v. Corel Corp». Berkeley Technology Law Journal, I 5 (I): 3-23. DOI: IO.I 5779/Z38XT28.

Mazzone, Jason (2006). "Copyfraud». New York University Law Review, 8I: I026-I Iо०. Disponible en http://papers.ssrn.com/sol3/papers.cfm?abstract_id $=787244$.

Newell, Bryce C. (2010). «Independent creation and originality in the age of imitated reality: A comparative analysis of copyright and database protection for digital models of real people». Brigham Young University International Law \& Management Review, 6 (2): 97-I3O. Disponible en http://papers.ssrn.com/sol3/papers. cfm?abstract_id=I709529.

Petri, Grischka (20I4). «The public domain vs. the museum: The limits of copyright and reproductions of two-dimensional works of art». Journal of Conservation and Museum Studies, I2 (I), 8: I-I2. DOI: I0.5334/jcms. IO2I 2 I 7 .

Ruiz Gallardo, Claudio (2010). Guías legales para bibliotecarios. Santiago: ONG Derechos Digitales. Disponible en https://www.derechosdigitales.org/wp-content/uploads/Guias_Legales_Bibliotecarios. pdf.

\section{SOBRE EL AUTOR}

Nicolás Bello Lagos es abogado. Licenciado en Ciencias Jurídicas y Sociales por la Universidad de Chile. Su correo electrónico es ngbellol@ gmail.com.

Este trabajo fue recibido el 3 I de octubre y aprobado el 28 de noviembre de 2016. 
